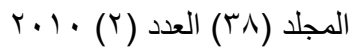
(ISSN 1815-316X)
مجلة زر اعة الر افدين

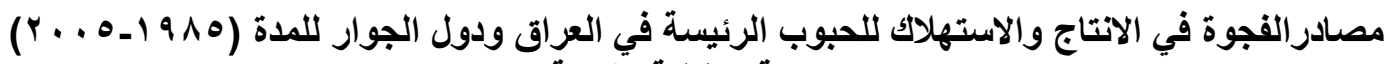 (دراسة تحليلية مقارنة)

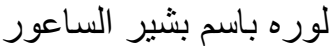 \\ قسم الاقتصاد الزر اعي / كلية الزر اعة والغابات / جامعة الموصل ـ العراق
}

\begin{abstract}
الخلاصة

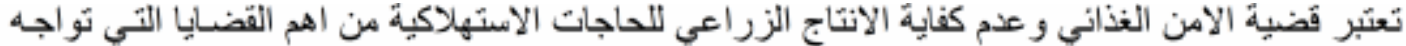

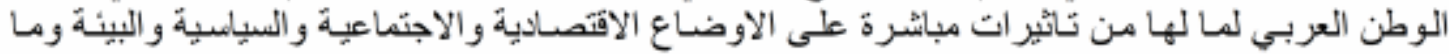

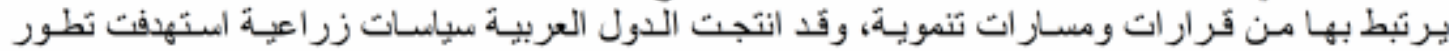

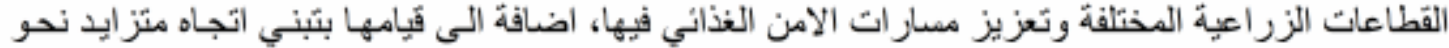

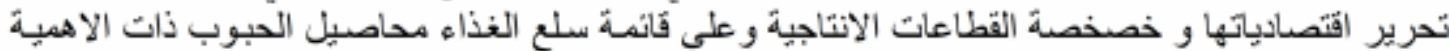

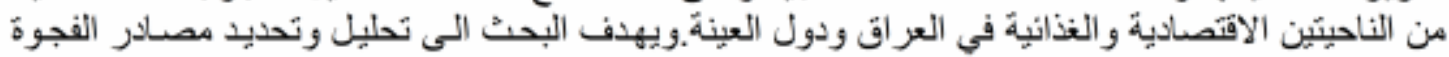

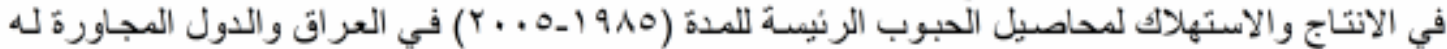

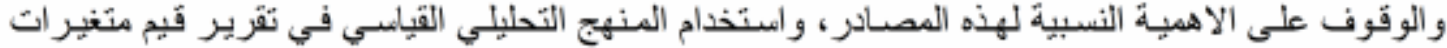

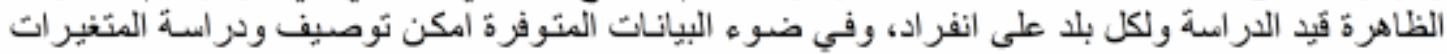

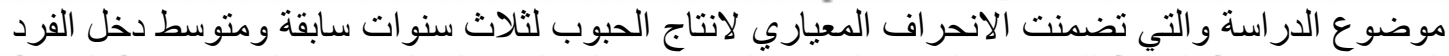

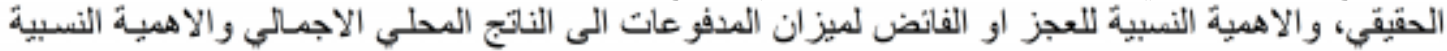

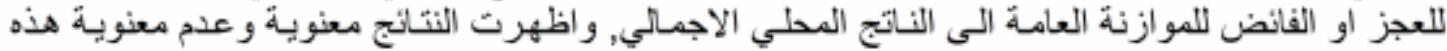

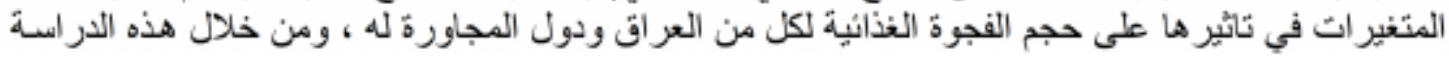

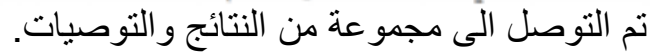

\section{المقدمة}

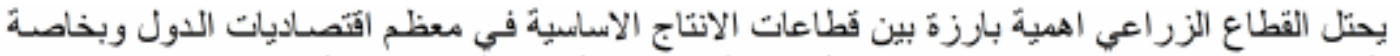

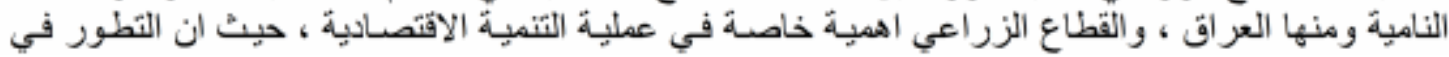

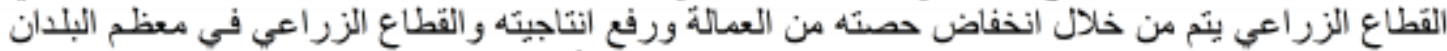

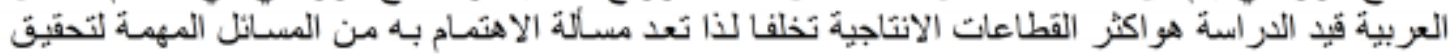

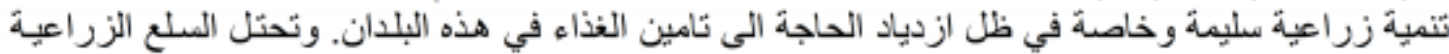

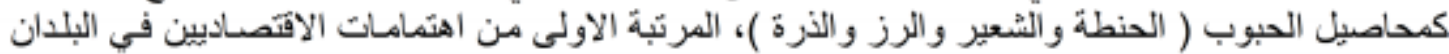

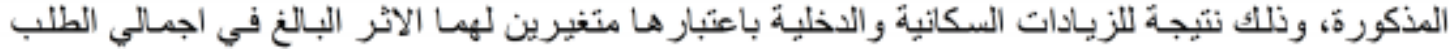

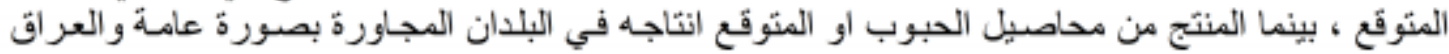

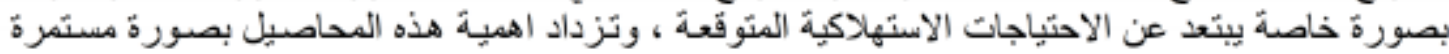
في محاولة لسد الاحتياجات الغذائية لهذه البلدان.

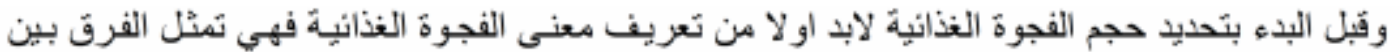

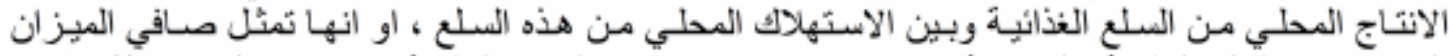

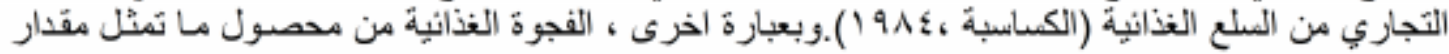

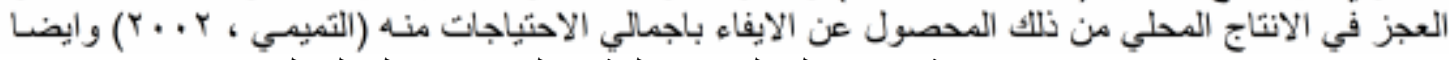

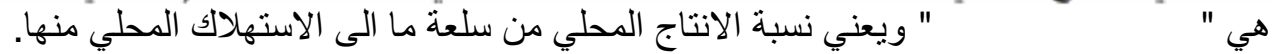

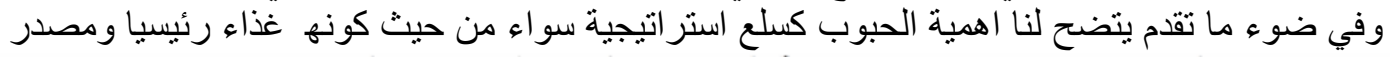

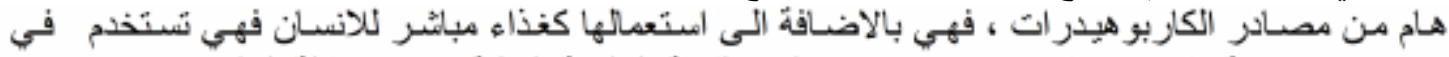

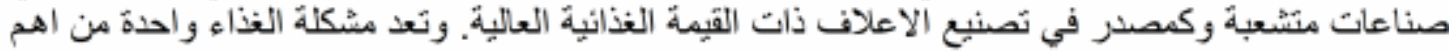

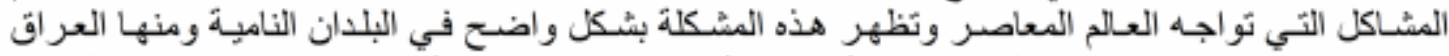

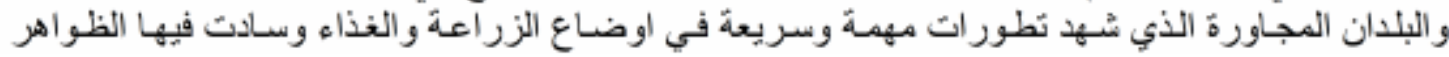
السلبية التي تمثلت بركود عرض السلع الزر اعية و عجز ها عن تلبية الطلب المنز ايد.

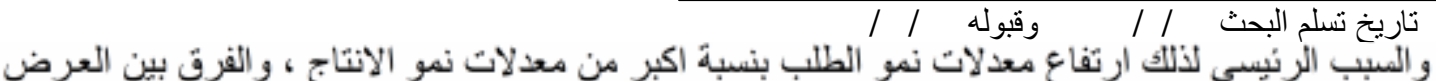

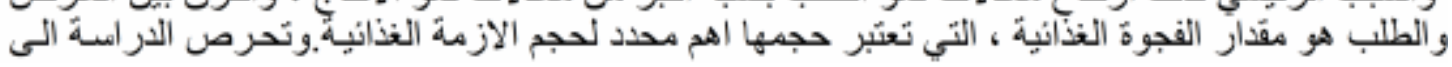




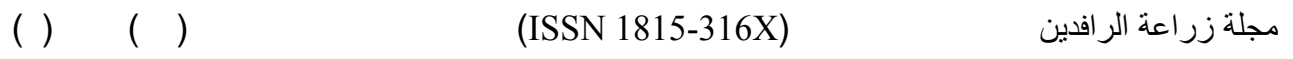

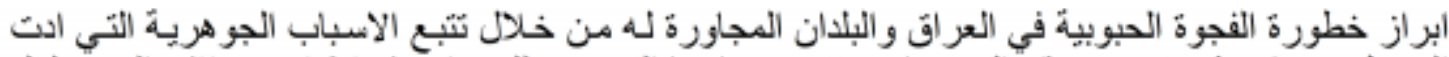

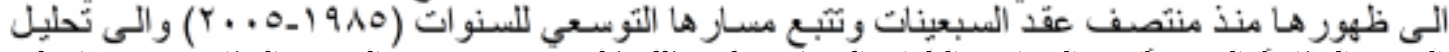

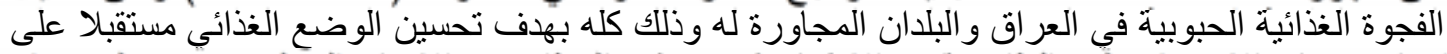

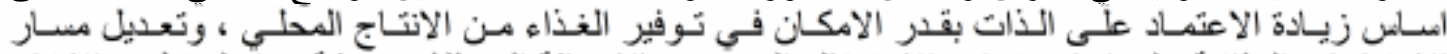

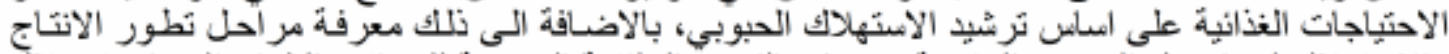

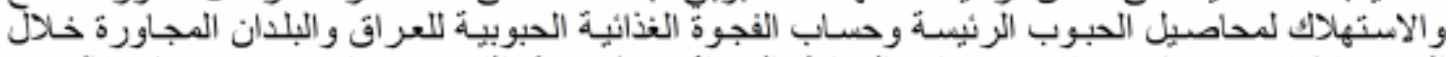

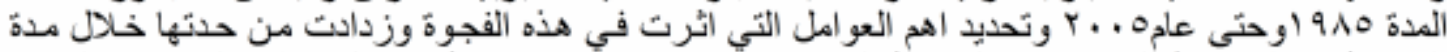

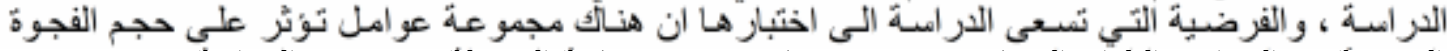

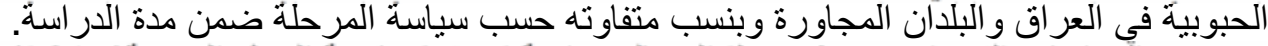

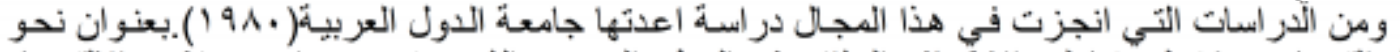

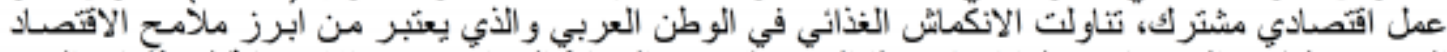

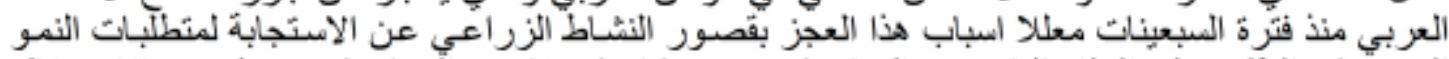

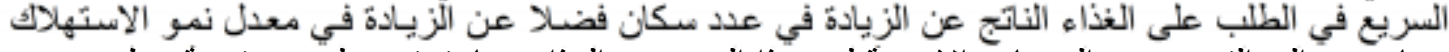

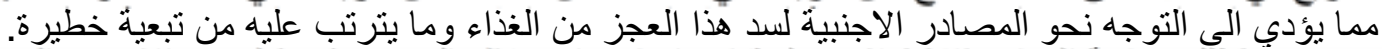

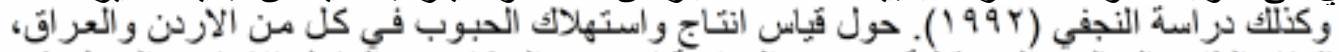

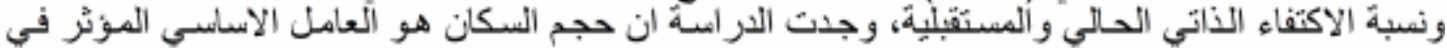

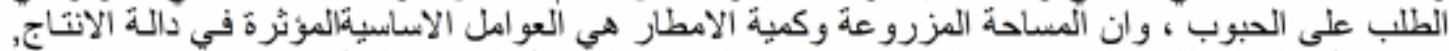

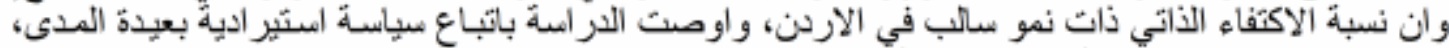

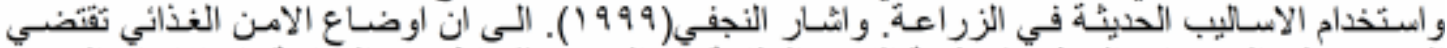

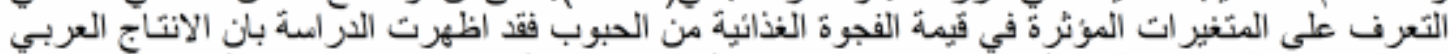

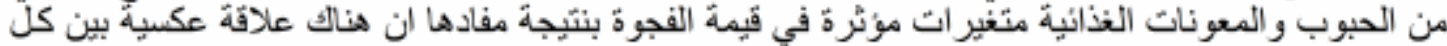

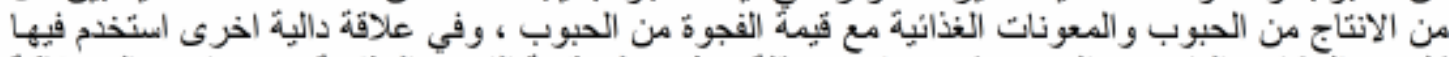

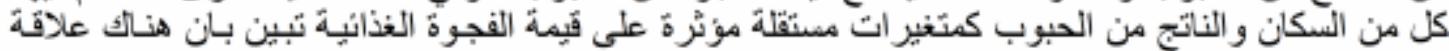

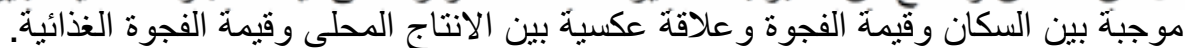

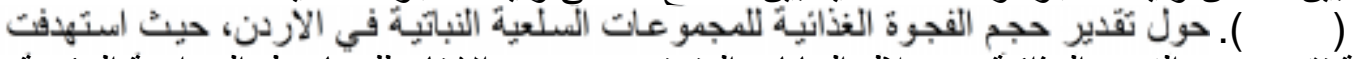

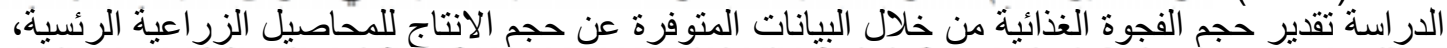

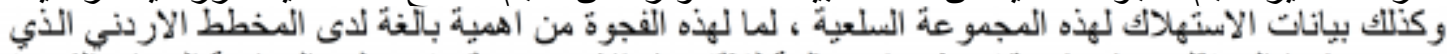

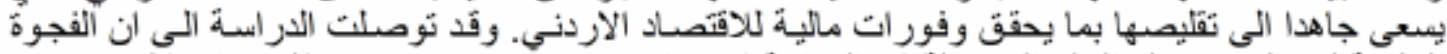

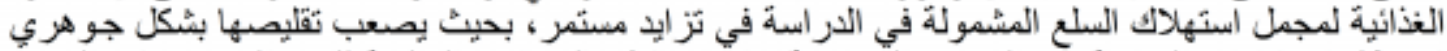

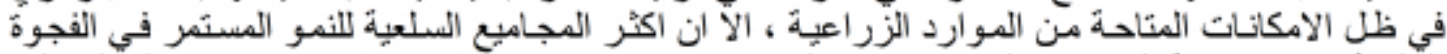

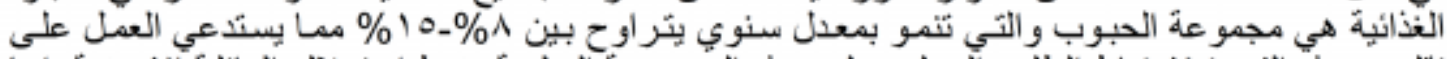

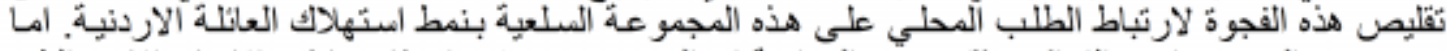

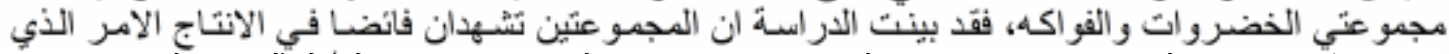
يساعد تثجيع انتاج المجمو عتين لاغر اض التصدير، لاسيما وان للاردن اسواق حالية لمثنل هذه المنتجات.

مواد البحث وطر ائقه

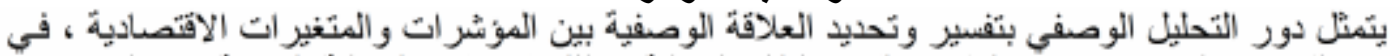

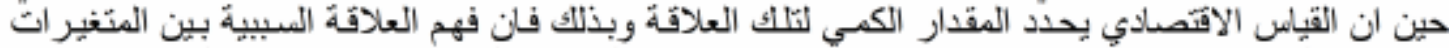

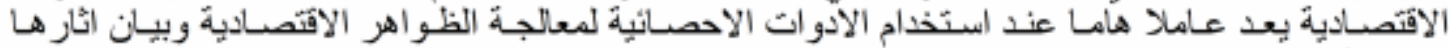

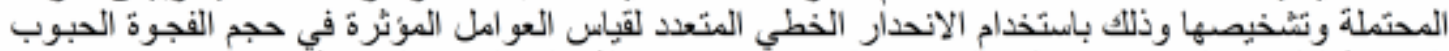

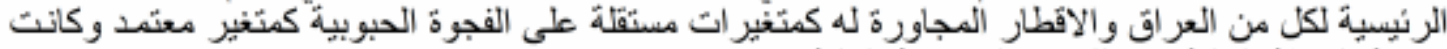

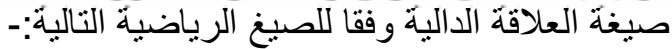
$\mathrm{Y}=\mathrm{B} 0+\mathrm{B} 1 \mathrm{x} 1+\mathrm{B} 2 \mathrm{x} 2+\mathrm{B} 3 \mathrm{x} 3+\mathrm{B} 4 \mathrm{x} 4+\mathrm{B} 5 \mathrm{x} 5+\ldots . .+\mathrm{Bnxn}+\mathrm{Ui}$

$$
\begin{aligned}
& -: \\
& =\mathrm{Y} \\
& \text { =X1 الانحر اف المعياري لانتاج الحبوب لثناث سنوات سابقة. X1 } \\
& \text { =X2 = = X2 }
\end{aligned}
$$

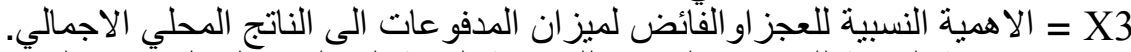

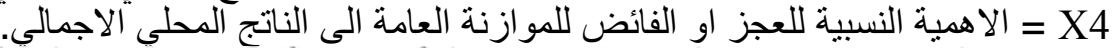

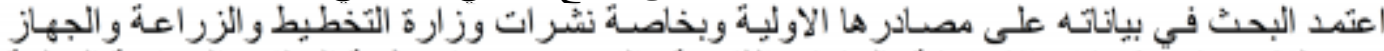

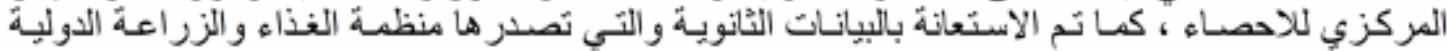



()$\quad()$
(ISSN 1815-316X)
مجلة زر اعة الر افدين

و المنظمة العربية للتنمية الزر اعية وبعض البحوث و الرسائل و الاطلريح ذات العلاقة وايضـا الثُبكة الدولية

\section{النتائج والمناقشة}

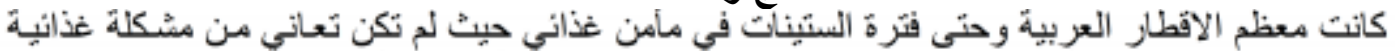

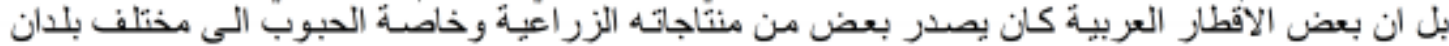

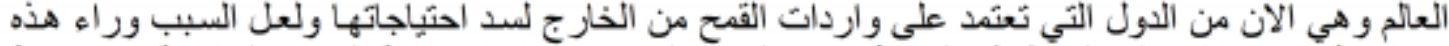

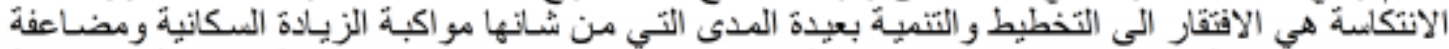

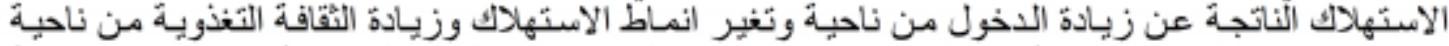

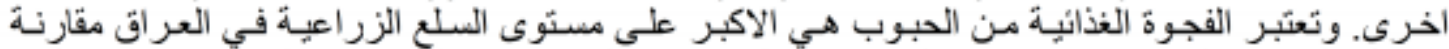

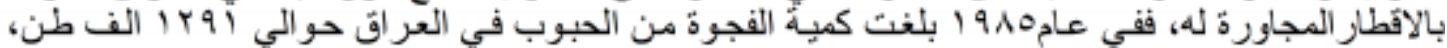

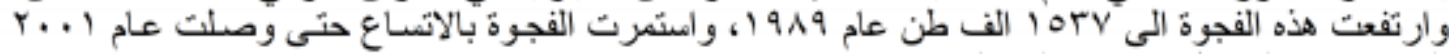
()

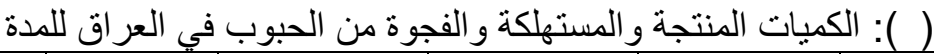

\begin{tabular}{|c|c|c|c|c|c|c|}
\hline لالتاج لثلاث المعياري & نسبة الاكتفاء & لدجوة لدو & الفجوة الحبوبية & (الف طن) & (الف طناج) & السنوات \\
\hline . & $x_{1}$ & NA & - & . & . & \\
\hline . & . & & - & . & . & \\
\hline . & . & . & - & . & & \\
\hline . & . & . & - & . & 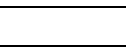 & \\
\hline . & . & . & - & . & . & \\
\hline . & . & . & - & . & . & \\
\hline . & . & & . - & . & & \\
\hline . & . & . & . - & . & & \\
\hline . & . & & . & . & . & \\
\hline . & . & . & .- & . & . & \\
\hline . & . & . &. & . & . & \\
\hline . & . & . &. & . & . & \\
\hline . & . & &.- & . & . & \\
\hline . & . & . & . - & . & . & \\
\hline . & . & . & . & . & . & \\
\hline . & . & & . - & . & & \\
\hline . & . & . &. & . & 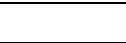 & \\
\hline . & . & &.- & . & & \\
\hline . & . & . &.- & & & \\
\hline . & . & &.- & & & \\
\hline . & . & & - & & & \\
\hline \multicolumn{7}{|c|}{ متوسط الفترات } \\
\hline-- & . & . & . - & . & . & - \\
\hline-- & . & . & - & . & . & - \\
\hline-- & . & & - & . & . & - \\
\hline-- & . & . &.- & & . & - \\
\hline-- & & . &.- & . & . & - \\
\hline
\end{tabular}

- - - احتسب الجدول من قبل الباحثة بالاعتماد على بيانات: -

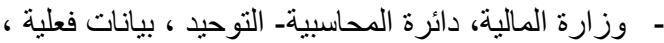

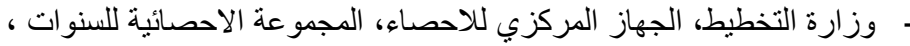

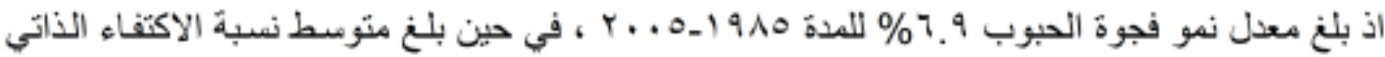

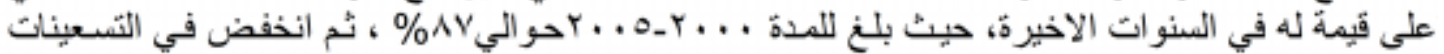

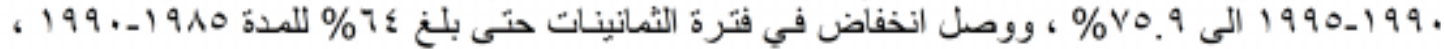
اما بالنسبة لجمهورية العربية السورية فقد تطورت كمية الفجوة الحبوبية خلال مدة الدراسة، حيث بلغت كمية

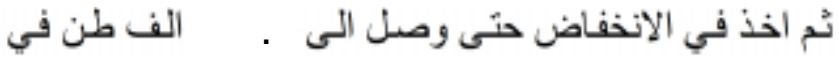

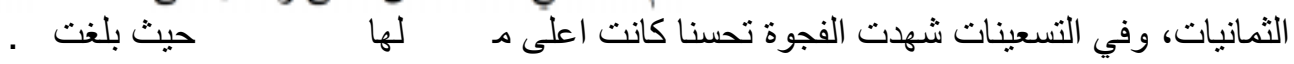



()$\quad()$
(ISSN 1815-316X)
مجلة زر اعة الر افدين

هو في عام شهدت بعدها الفجوة انخفاضا كبير بسبب زيادة الانتاج من الحبوب حيث انخفضت فيت

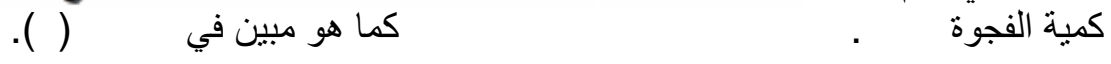

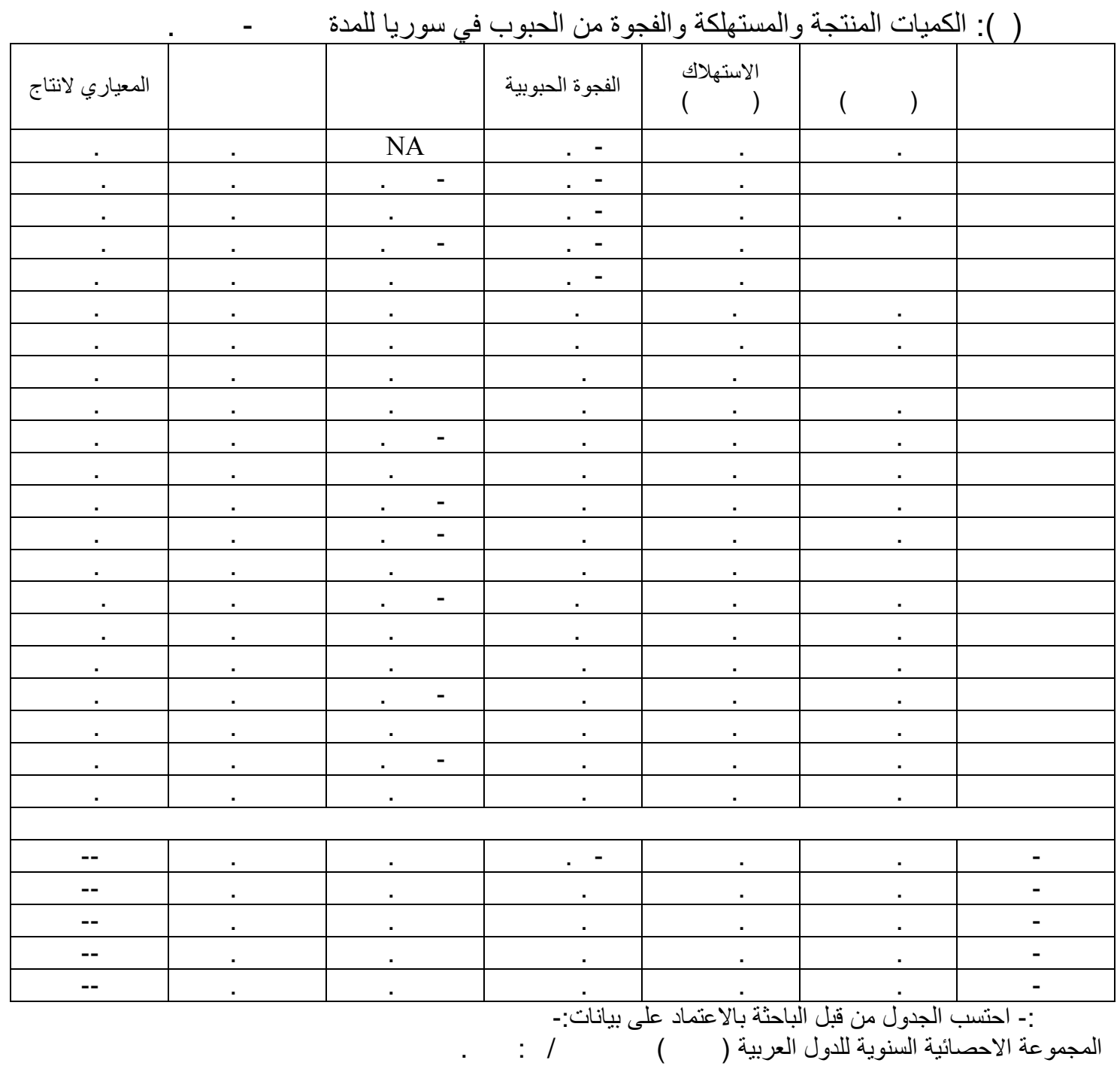

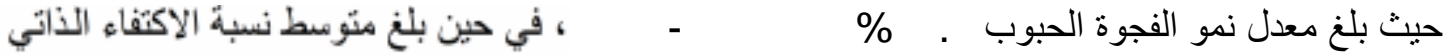
$\%$
\% \% حيث وصل اعلى قيمة له خلال المدة

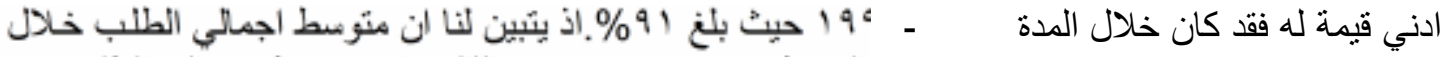

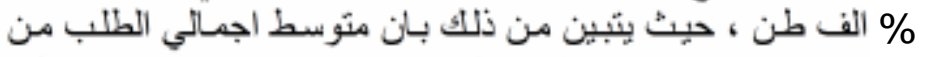

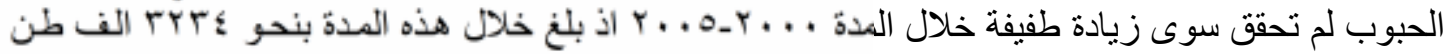

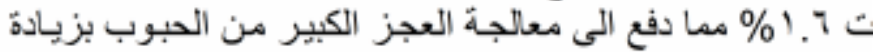

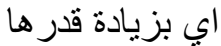

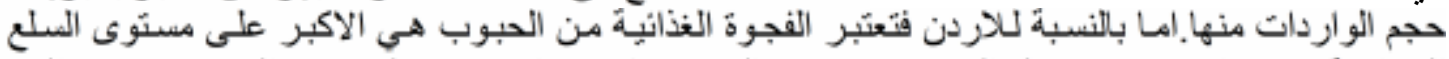

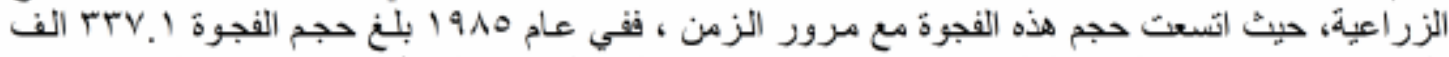

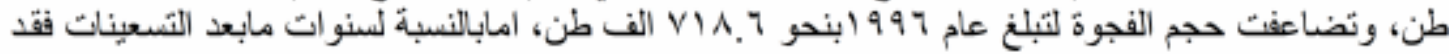

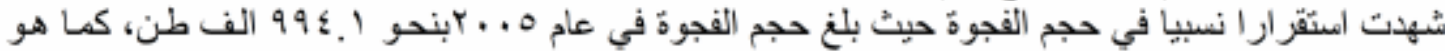

مبين في

( ) ) الكميات المنتجة والمستهلكة والفجوة من الحبوب في الاردن للمدة 

()$\quad(\quad)$
(ISSN 1815-316X)
مجلة زر اعة الر افدين

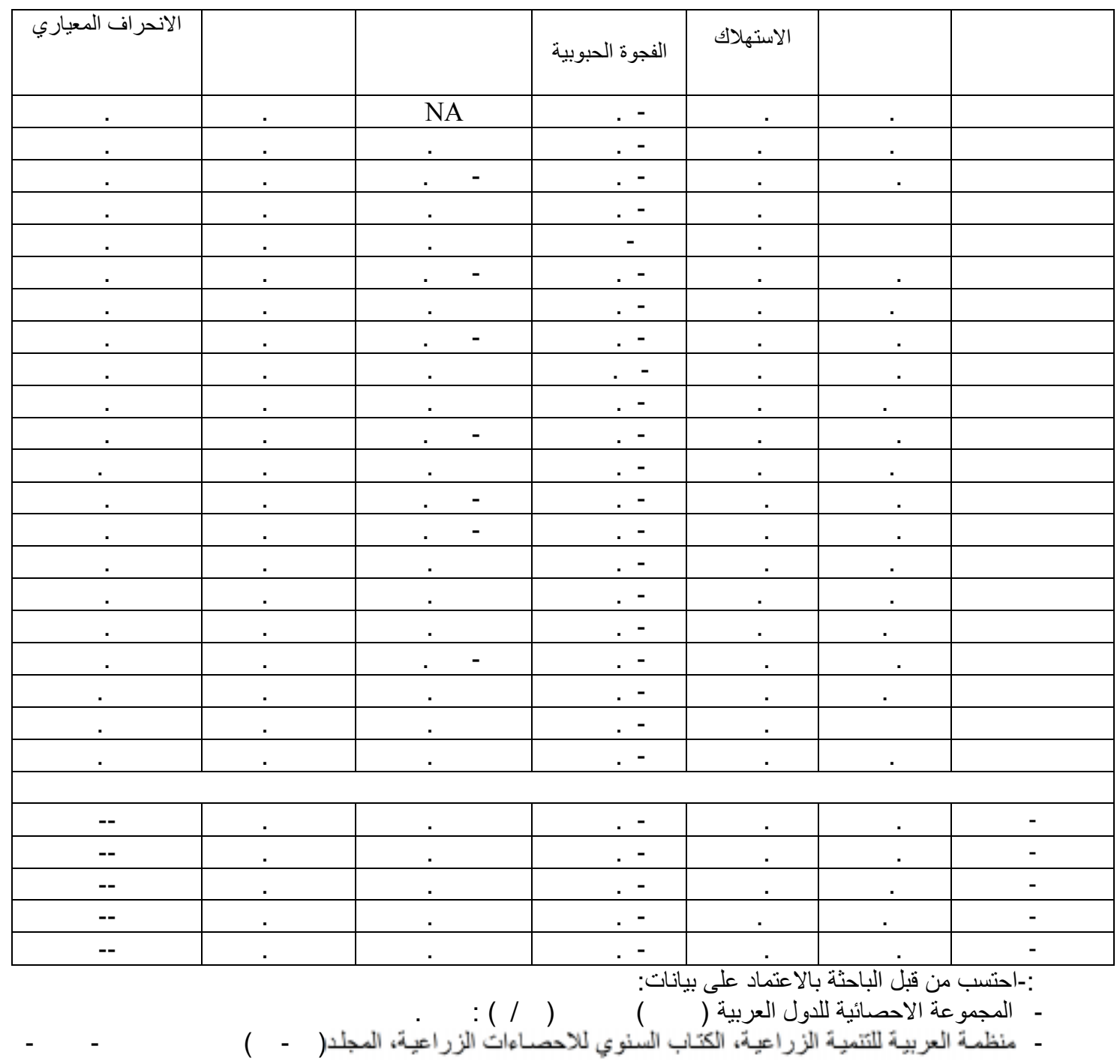

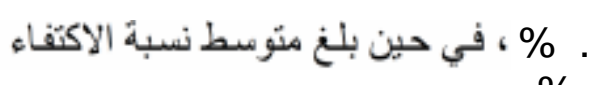

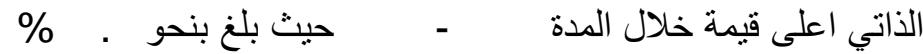

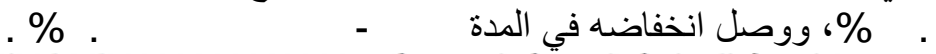

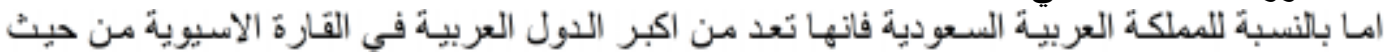

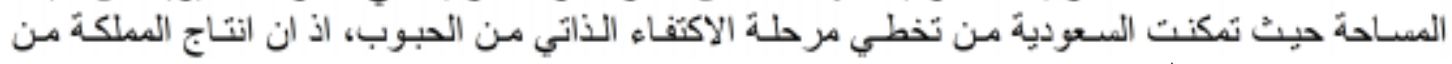

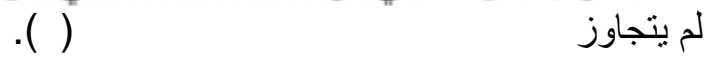

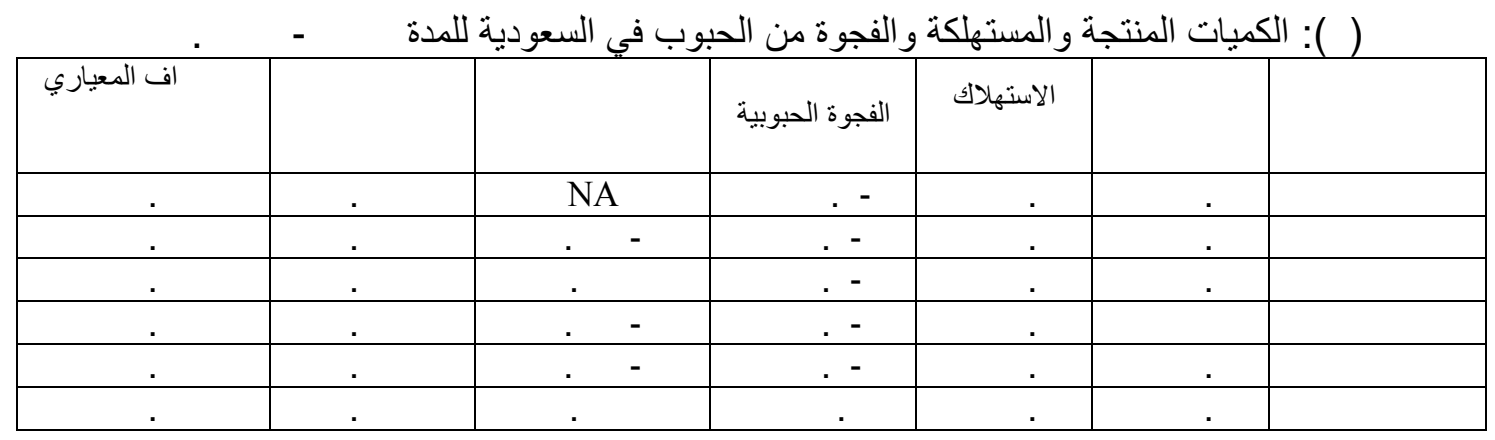



()$\quad()$
(ISSN 1815-316X)
مجلة زر اعة الر افدين

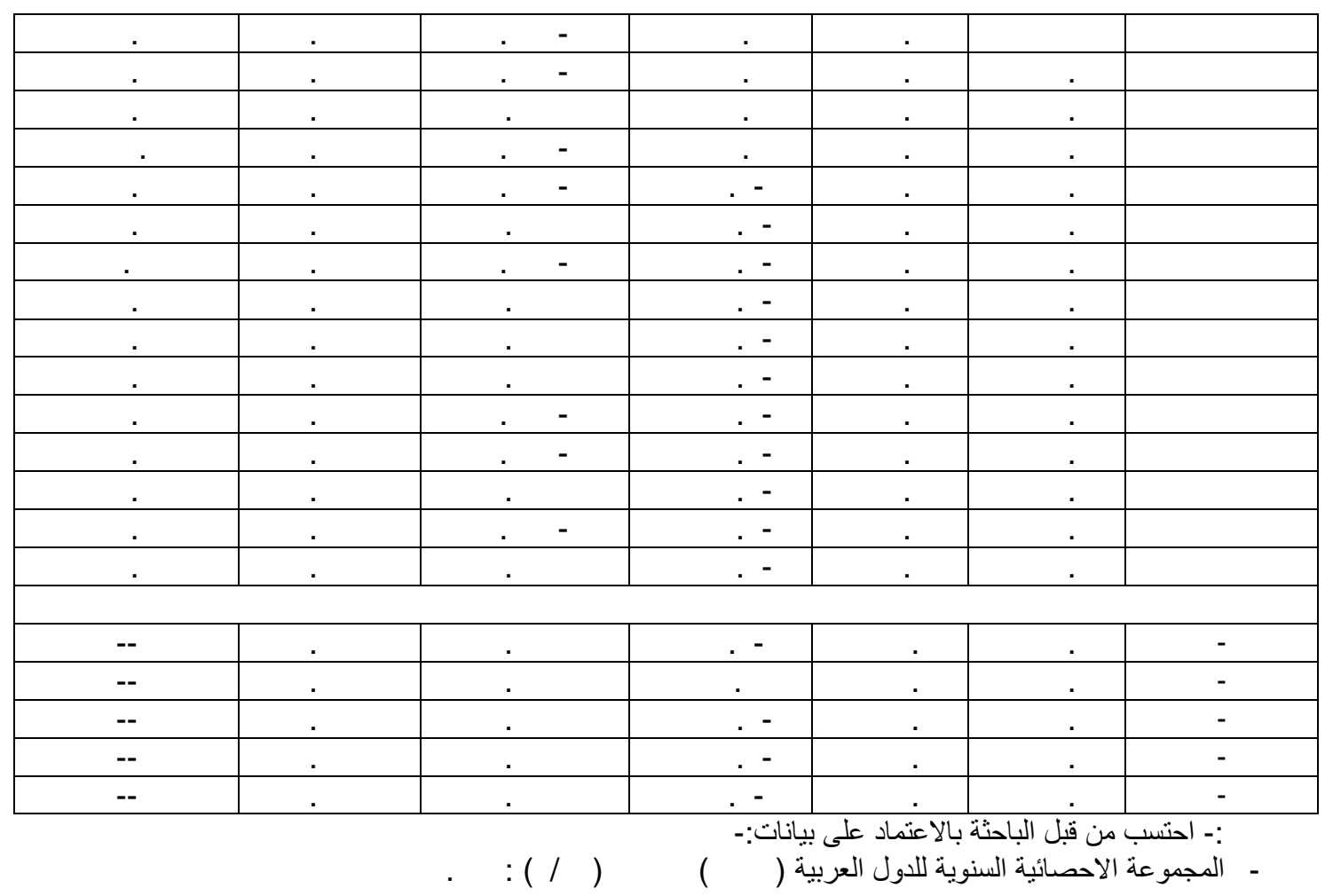

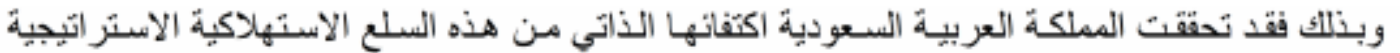

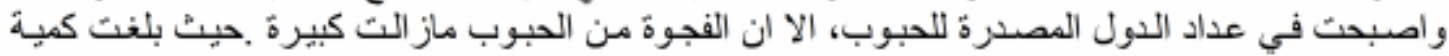

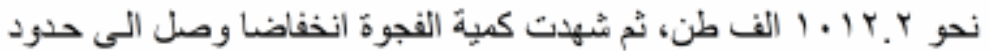

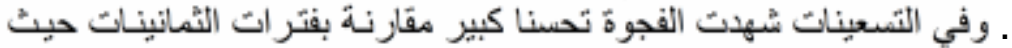

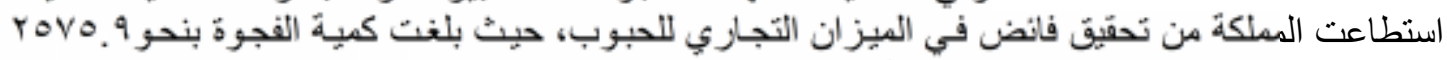

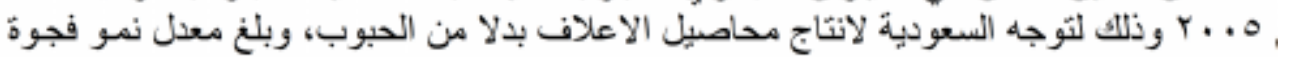

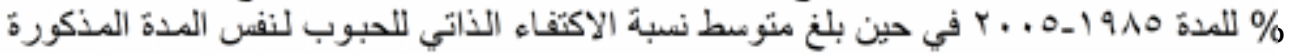

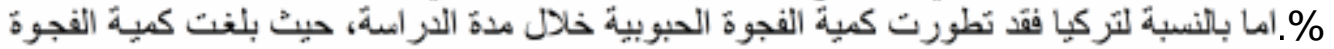

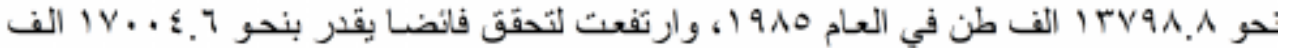

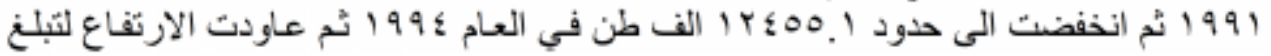

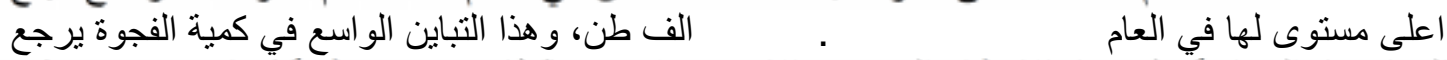

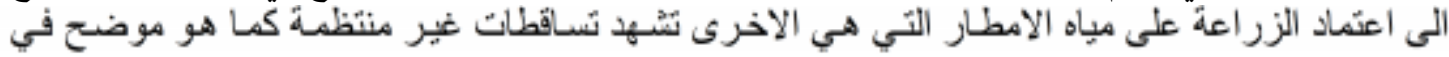

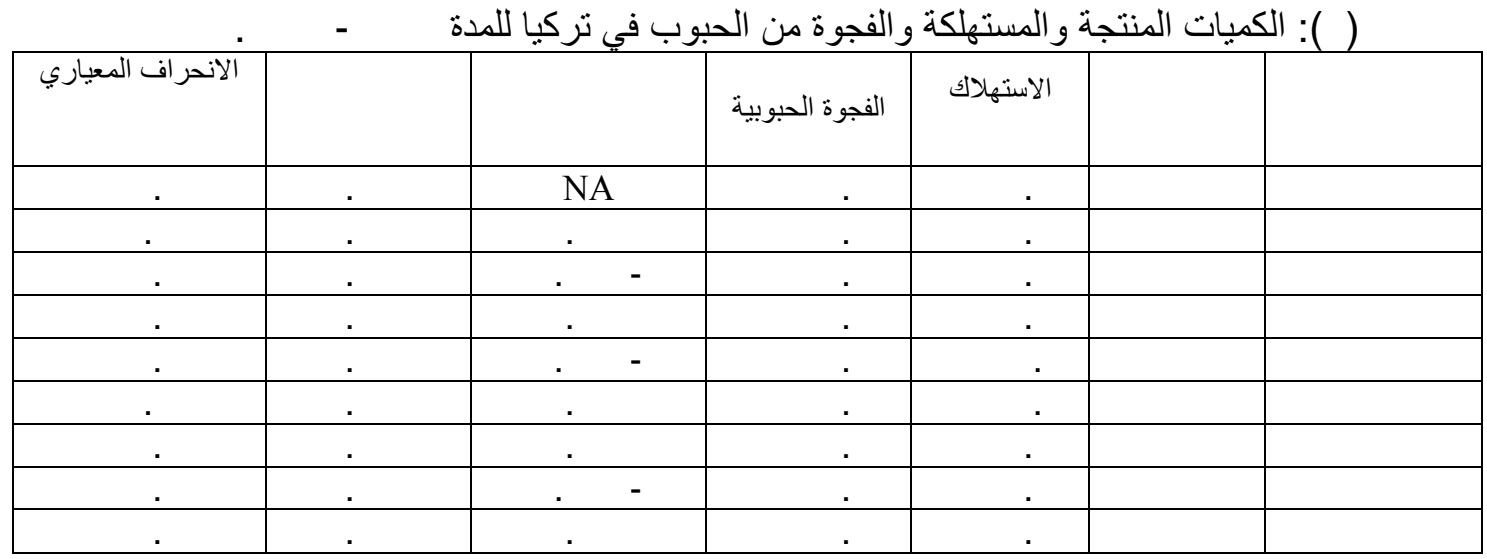



()$\quad()$
(ISSN 1815-316X)
مجلة زر اعة الر افدين

\begin{tabular}{|c|c|c|c|c|c|c|c|}
\hline 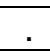 & . & . & - & . & & & \\
\hline . & . & . & & . & . & & \\
\hline . & . & . & & . & . & & \\
\hline . & . & . & & . & . & & \\
\hline . & . & . & & . &. & & \\
\hline . & . & . & - & . & . & & \\
\hline . & . & . & & . & . & & \\
\hline . & . & & - & . & . & & \\
\hline . & . & . & & . &. & & \\
\hline . & . & . & & . & $\dot{.}$ & & \\
\hline . & . & . & & . & . & & \\
\hline . & . & . & & . & . & & \\
\hline & & & & & & & \\
\hline -- & . & . & & . & . & . & - \\
\hline-- & . & . & & . & . & . & - \\
\hline-- & . & . & & . & . & . & - \\
\hline-- & . & . & & . & . & . & - \\
\hline-- & . & . & & . & . & . & - \\
\hline
\end{tabular}

1- United Nation(1995),Fao, Food Outlook, Food And Agriculture Organization Of The U.N,October, Rome.

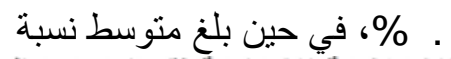

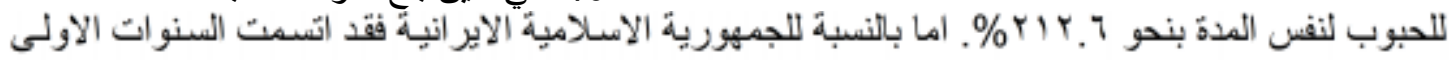

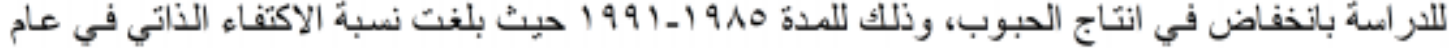

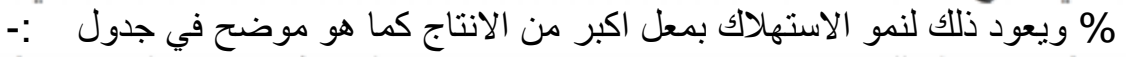

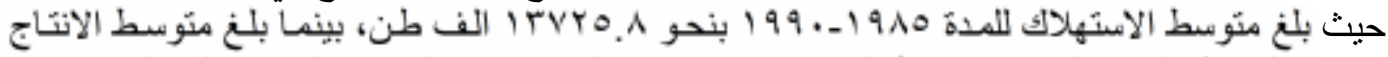

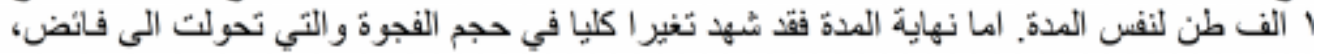
$\%$

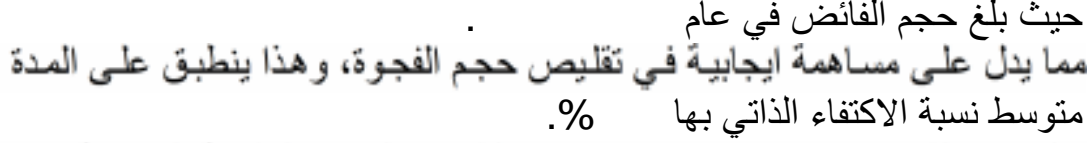

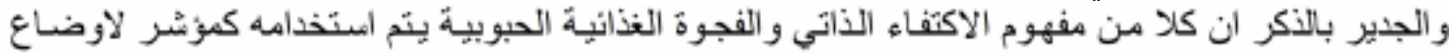

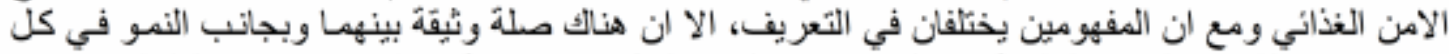

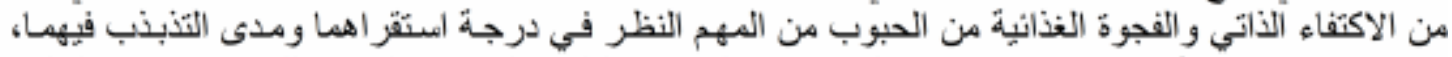

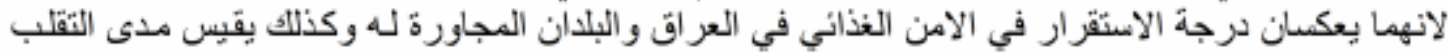
في انتاج الحبوب الرئيسية.

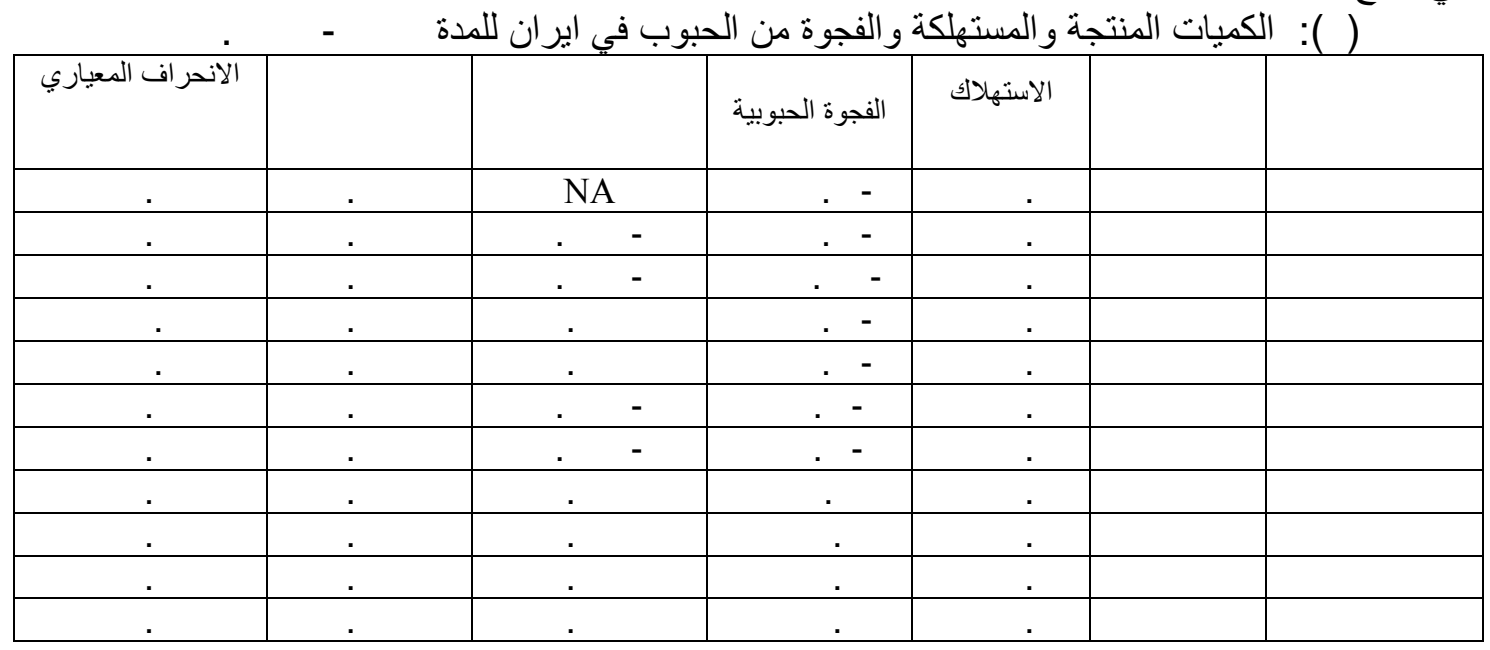



()$\quad()$
(ISSN 1815-316X)
مجلة زر اعة الر افدين

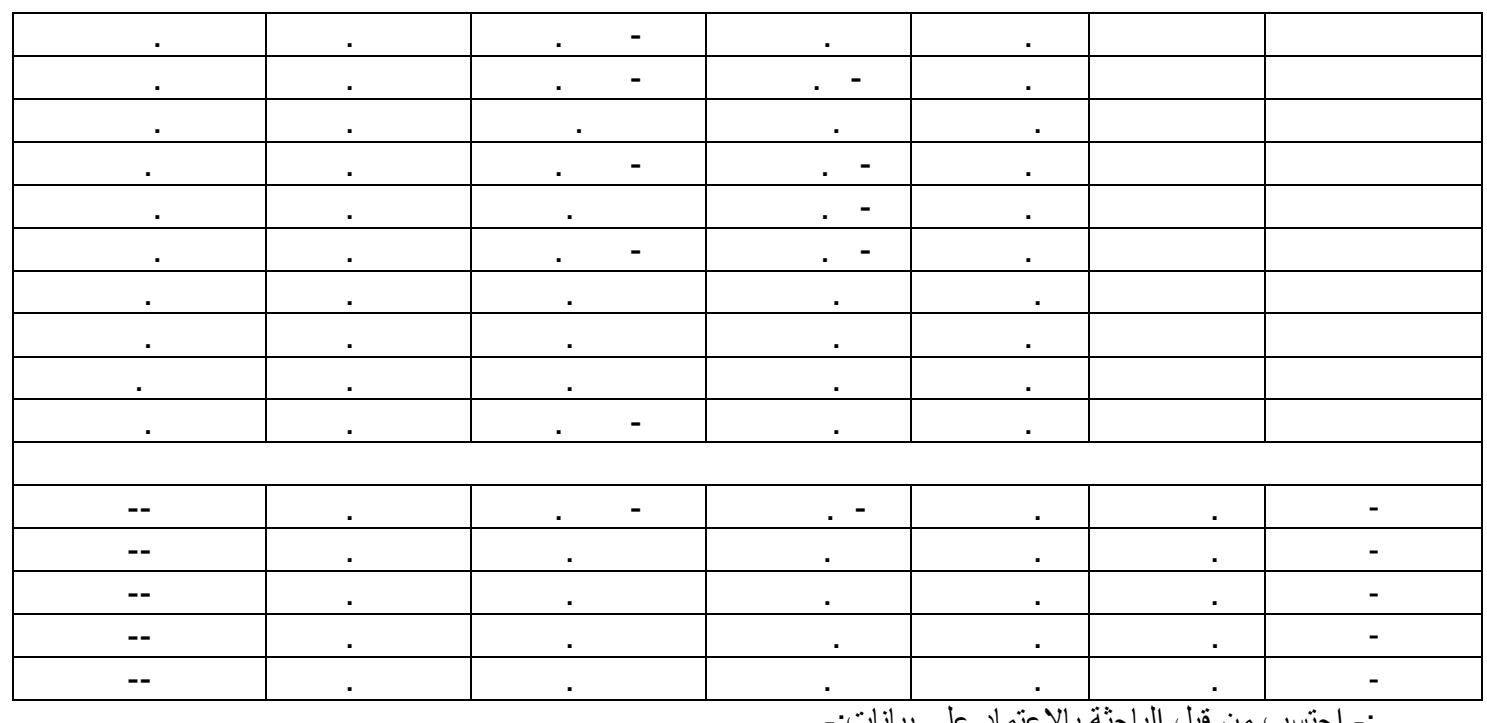

1- United Nation(1995),Fao , Food Outlook, Food And Agriculture Organization Of The U.N,October, Rome.

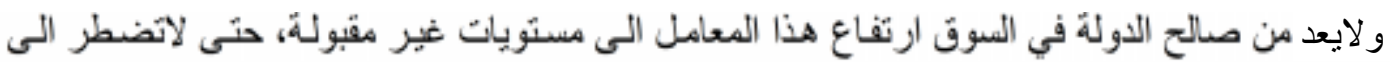

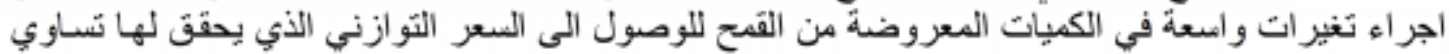

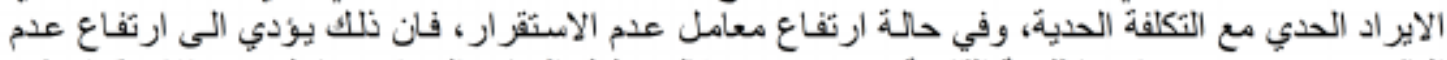

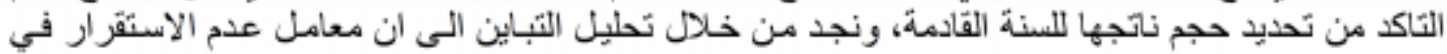

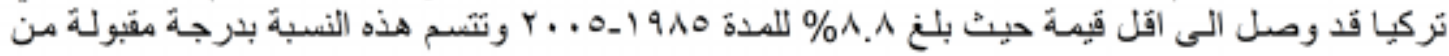

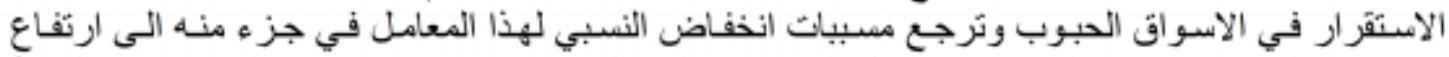

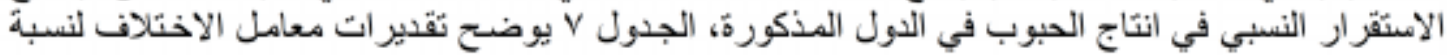

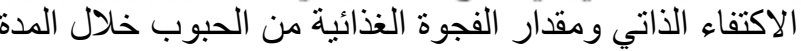

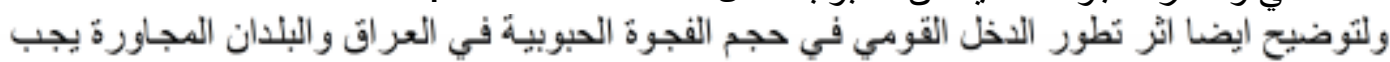

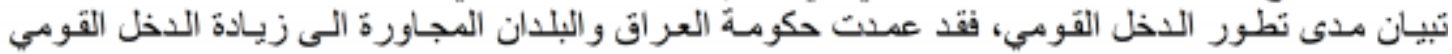

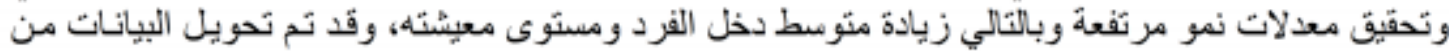

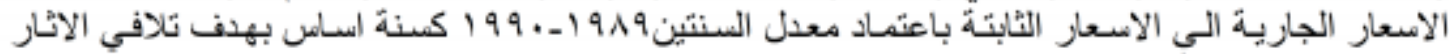

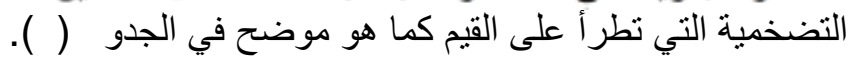

( ) ) الاستقرار في الاكتفاء الذاتي والفجوة الغذائية من الحبوب للعر اق و البلدان المجاورة له خلال

\begin{tabular}{|c|c|c|c|c|c|}
\hline الفجوة الغذائية & & & الفجوة الغذائية & & \\
\hline . & . & سعودية & . & . & \\
\hline . &. & تركيا & . & . & سوريا \\
\hline. & . & ايران & 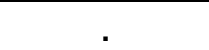 & . & \\
\hline
\end{tabular}

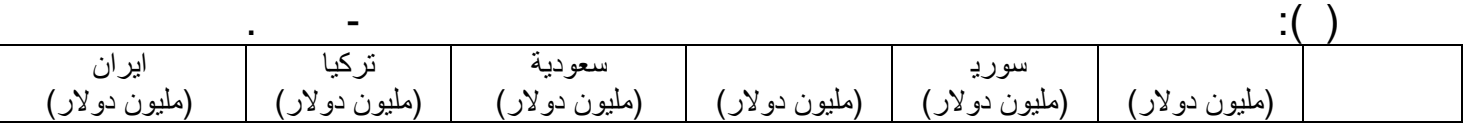



()$\quad()$
(ISSN 1815-316X)
مجلة زر اعة الر افدين

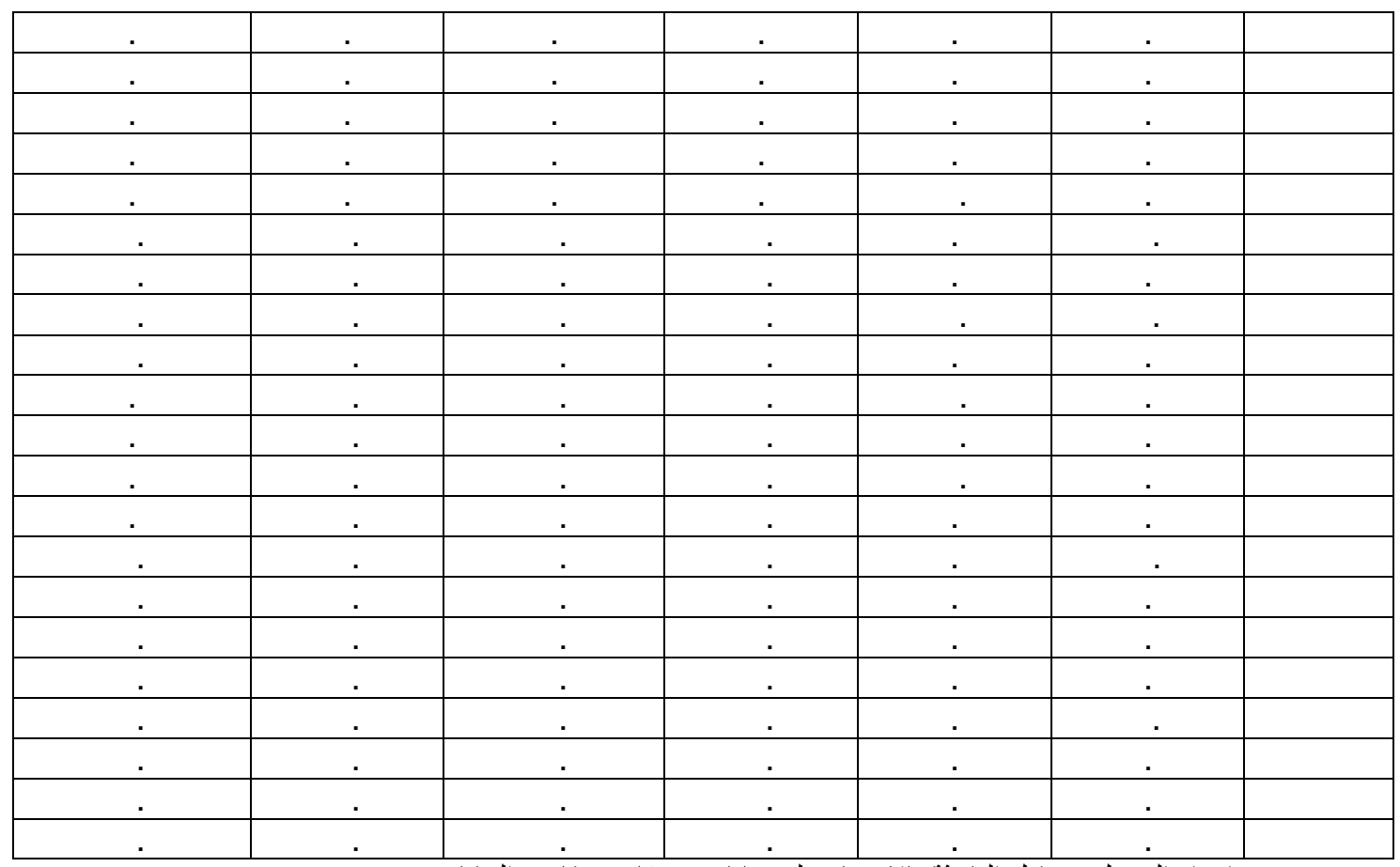

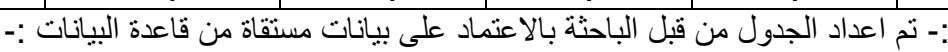

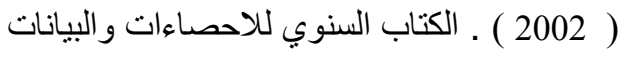

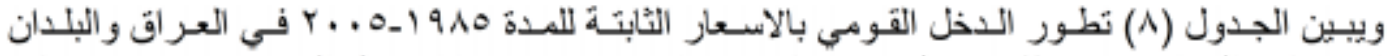

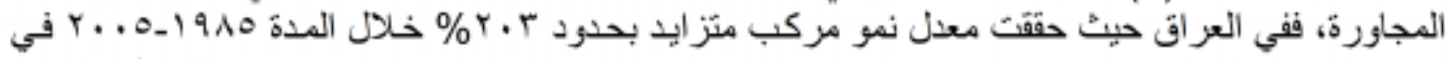

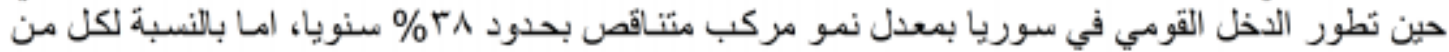

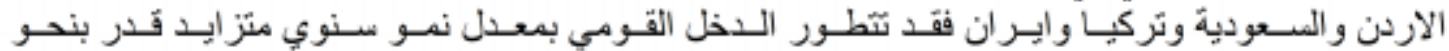

$$
\text { \% \% \% \% }
$$

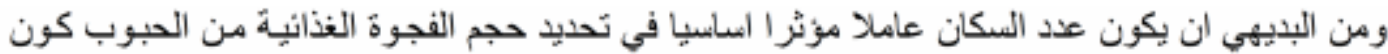

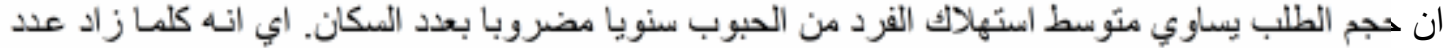

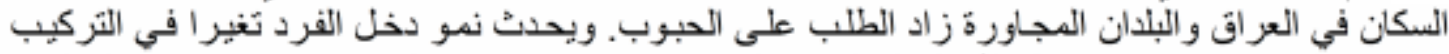

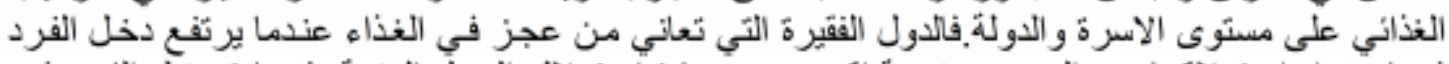

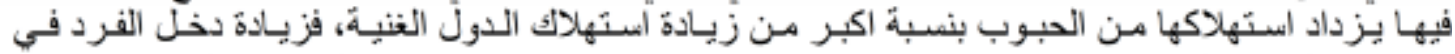

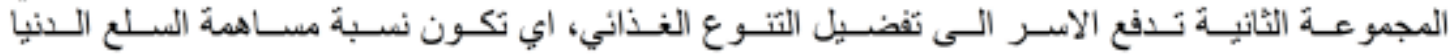

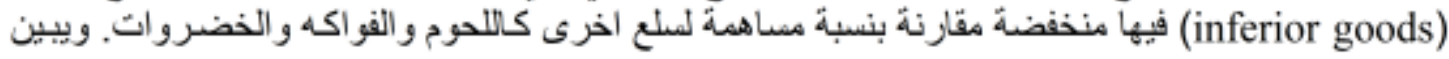

( )

\begin{tabular}{|c|c|c|c|c|c|c|c|c|c|c|c|c|}
\hline \multicolumn{2}{|c|}{ ايران } & \multicolumn{2}{|c|}{ تركيا } & \multicolumn{2}{|c|}{ سعودية } & & & \multicolumn{2}{|c|}{ سوريا } & \multicolumn{3}{|c|}{.11} \\
\hline- & 奈 & - & 疍 & - & $\widehat{s}$ & - & 争 & - & 承 & - & 承 & \\
\hline$\smile$ & 题 & $\smile$ & 量 & 一 & 㩊 & 一 & 3 & $\smile$ & 哹 & $\smile$ & 3 & \\
\hline . & . & . & . & . & . &. & . &. & . & . & & \\
\hline . & . & . & . & . &. & . &. & . &. & . & & \\
\hline . &. &. &. & . &. & . & . &. & . & . & & \\
\hline$\cdot$ & & . & . & . &. & . &. &. &. & . & & \\
\hline$\dot{-}$ & . &. & . & . &. & . & . &. & . & . &. & \\
\hline . & . & . & . & . & . & . & . & . & . & . & . & \\
\hline . &. &. & . & . & . & . & . & . & . & . & & \\
\hline
\end{tabular}



()$\quad()$
(ISSN 1815-316X)
مجلة زر اعة الر افدين

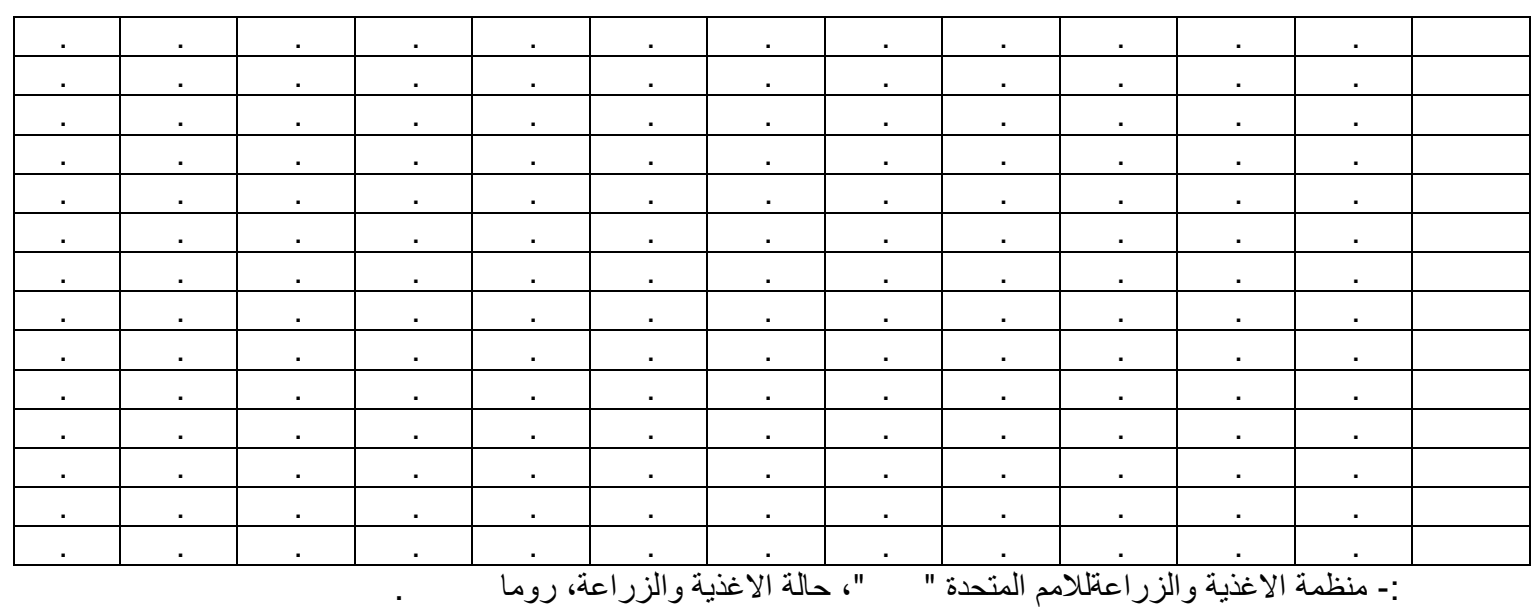

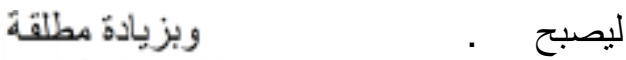

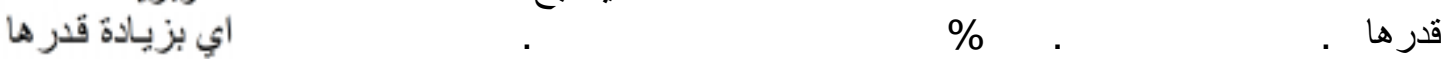

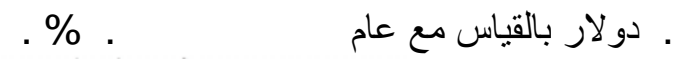

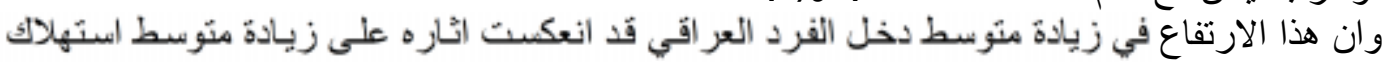

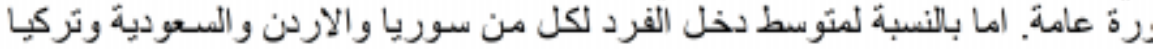

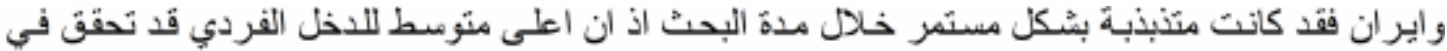

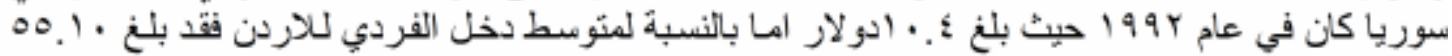

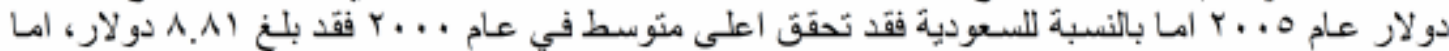

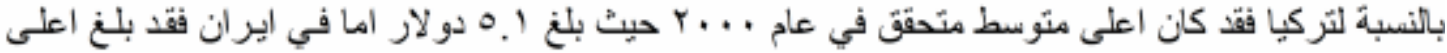

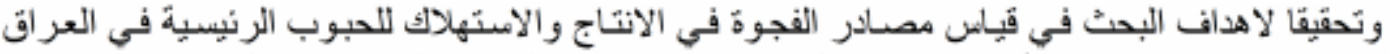

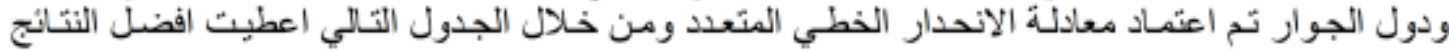

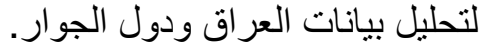

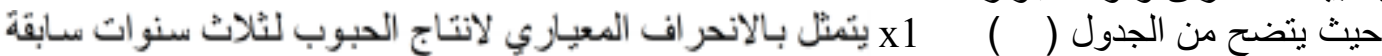

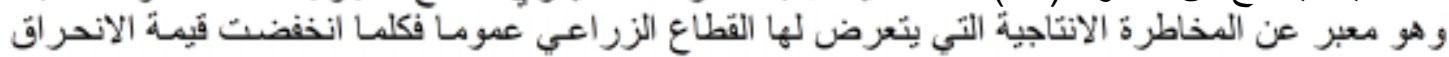

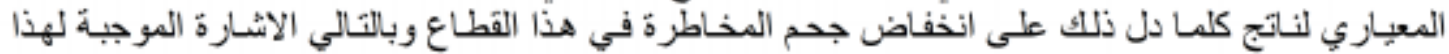

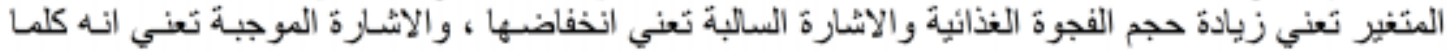

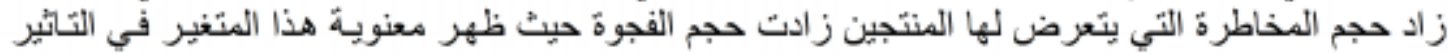
على حجم الفجوة في كل من العر اق وسوريا وظهرت علاقة الفئ المتغير المذكور عكسية مع المتغير المتعدد وهذه

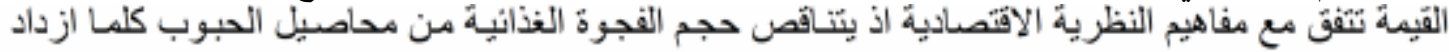

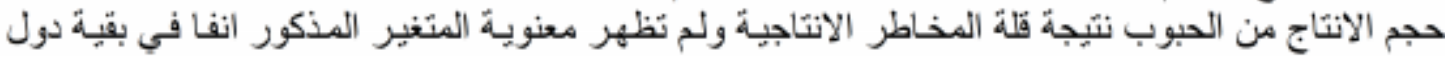
العينة.

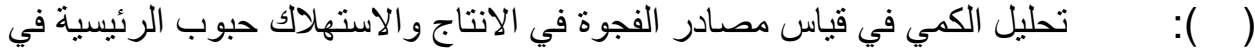

\begin{tabular}{|c|c|c|c|c|c|c|c|}
\hline & & $\mathrm{Xi}$ & $\mathrm{X} 1$ & $\mathrm{X} 2$ & X3 & $\mathrm{X} 4$ & \\
\hline & \multirow{2}{*}{$\begin{array}{c}\mathrm{R}^{2}=0.60 \\
\mathrm{~F}=8.76 \\
\mathrm{D} . \mathrm{W}=2.21\end{array}$} & $\mathrm{Bi}$ & -0.0002 & -0.0081 & 0.0001 & 0.0045 & \multirow{2}{*}{ ون والئتية } \\
\hline & & $t^{*}$ & $(-1.85)$ & $(-1.45)$ & $(1.24)$ & $(3.50)$ & \\
\hline \multirow{2}{*}{ سوريا } & \multirow{2}{*}{$\begin{array}{c}\mathrm{R}^{2}=0.58 \\
\mathrm{~F}=7.99 \\
\mathrm{D} . \mathrm{W}=1.97\end{array}$} & $\mathrm{Bi}$ & -1.23 & -0.103 & -0.188 & 0.333 & \multirow{2}{*}{ لورغارتمية } \\
\hline & & $t^{*}$ & $(-4.78)$ & $(-0.16)$ & $(-1.50)$ & $(2.19)$ & \\
\hline
\end{tabular}




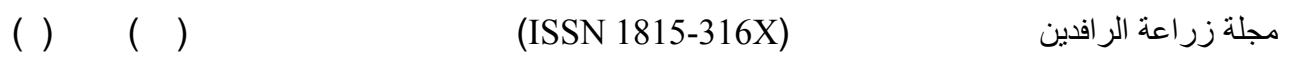

\begin{tabular}{|c|c|c|c|c|c|c|c|}
\hline & $\mathrm{R}^{2}=0.63$ & $\mathrm{Bi}$ & -0.069 & 1.040 & 0.0008 & 0.007 & \multirow[t]{2}{*}{ لور غارتمية } \\
\hline & D. $W=1.39$ & $\mathrm{t}^{*}$ & $(-1.07)$ & $(3.64)$ & $(0.02)$ & $(0.14)$ & \\
\hline \multirow{2}{*}{ سعودية } & \multirow{2}{*}{$\begin{array}{c}\mathrm{R}^{2}=0.44 \\
\mathrm{~F}=5.02 \\
\mathrm{D} . \mathrm{W}=2.24\end{array}$} & $\mathrm{Bi}$ & -0.121 & 2.96 & 0.008 & -0.023 & \multirow{2}{*}{ ل لور غارتمية } \\
\hline & & $\mathrm{t}^{*}$ & $(-0.84)$ & $(2.47)$ & $(0.13)$ & $(-0.04)$ & \\
\hline \multirow{2}{*}{ تركيا } & \multirow{2}{*}{$\begin{array}{c}\mathrm{R}^{2}=0.13 \\
\mathrm{~F}=1.78 \\
\mathrm{D} . \mathrm{W}=1.28\end{array}$} & $\mathrm{Bi}$ & 0.065 & 0.101 & 0.048 & -0.058 & \multirow{2}{*}{ لو لور غارتمية } \\
\hline & & $\mathrm{t}^{*}$ & $(0.91)$ & $(1.31)$ & $(1.24)$ & $(-2.11)$ & \\
\hline \multirow[b]{2}{*}{ ايران } & \multirow{2}{*}{$\begin{array}{c}\mathrm{R}^{2}=0.23 \\
\mathrm{~F}=2.57 \\
\mathrm{D} . \mathrm{W}=1.77\end{array}$} & $\mathrm{Bi}$ & -901 & 2614 & -1259 & 103 & \multirow{2}{*}{ كن الئمينة } \\
\hline & & $\mathrm{t}^{*}$ & $(-1.32)$ & $(1.92)$ & $(-2.12)$ & $(0.24)$ & \\
\hline
\end{tabular}

:- من عمل الباحثة بالاعتماد على نتائج التحليل الكمي لدول العينة.

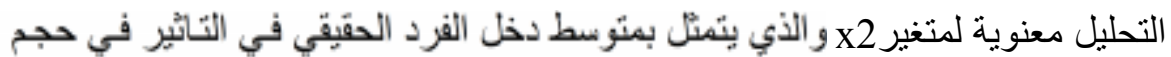

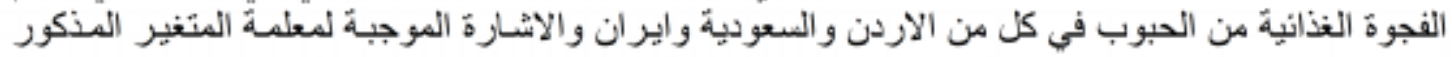

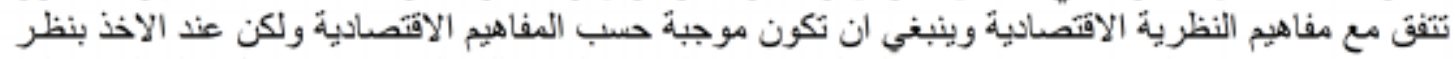

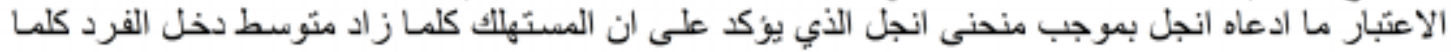

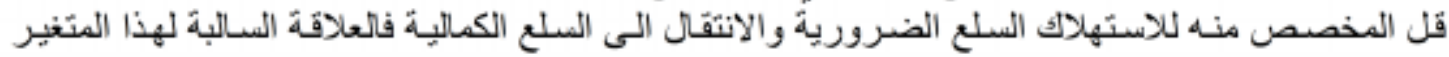

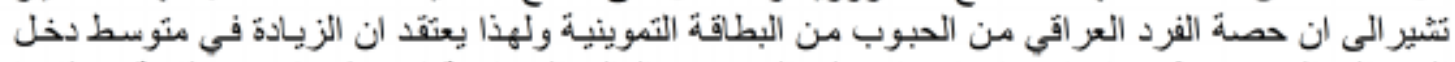

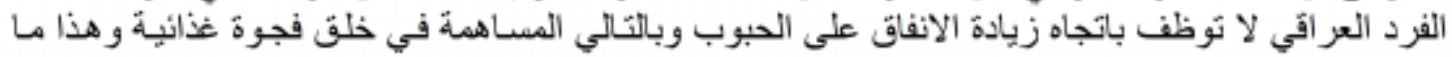

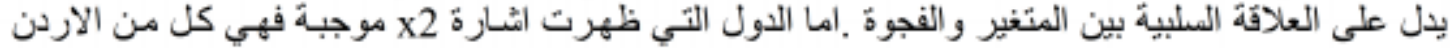

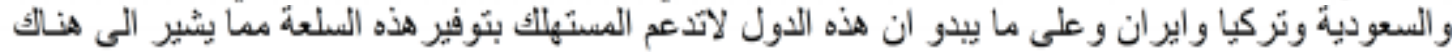

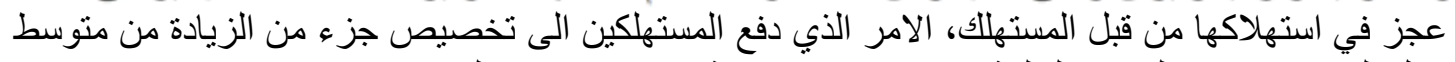

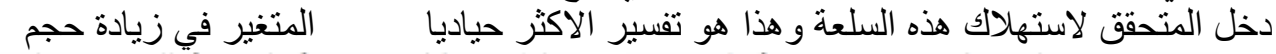

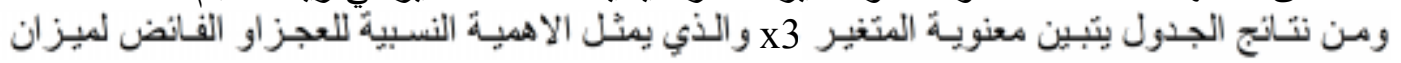

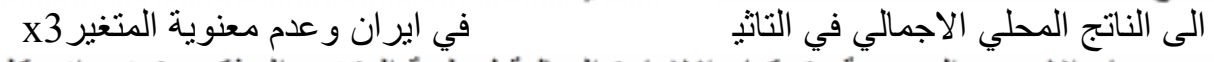

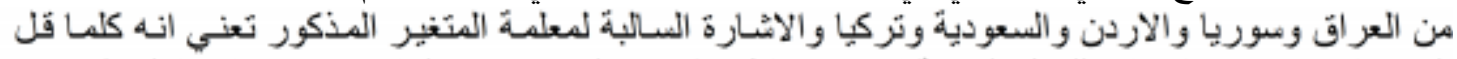

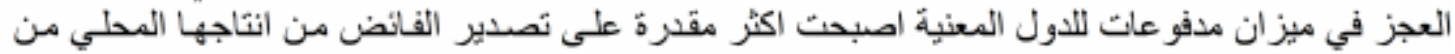

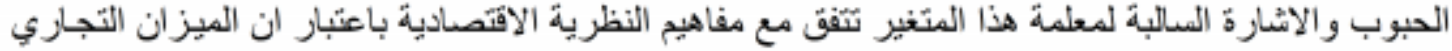

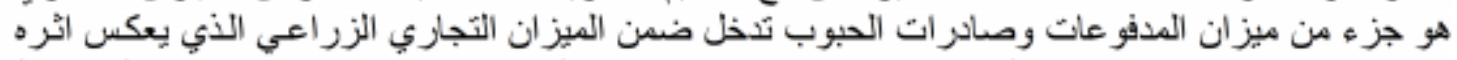

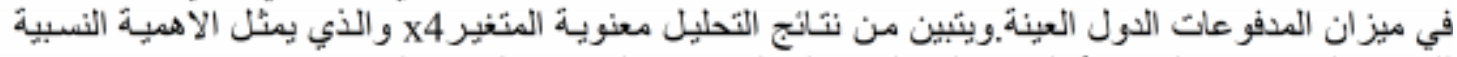

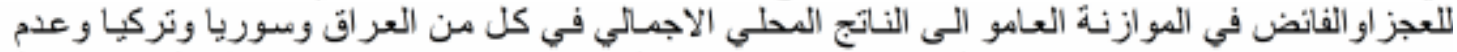

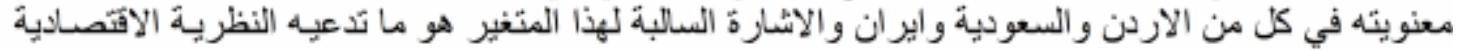

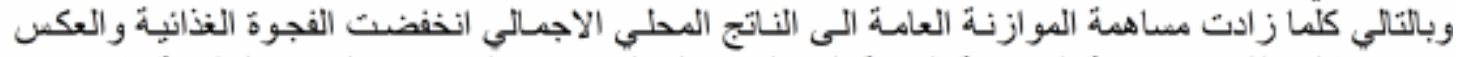

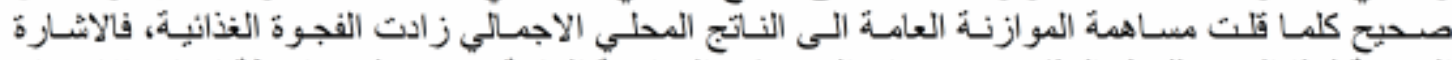

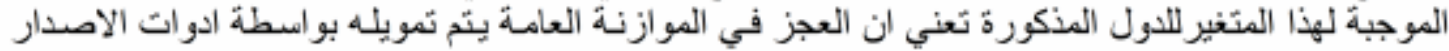

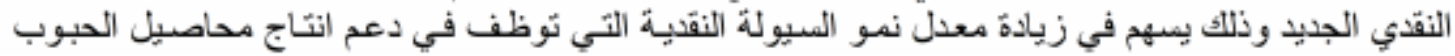
لتعدد وتنوع استخدماتها الغذائية و الصناعية.

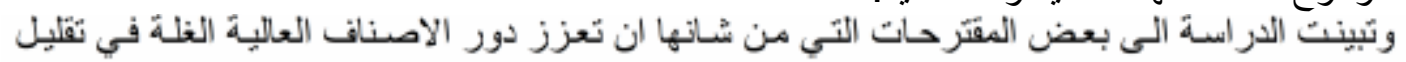

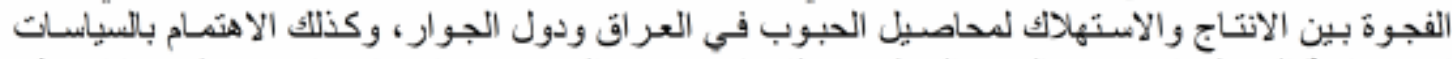

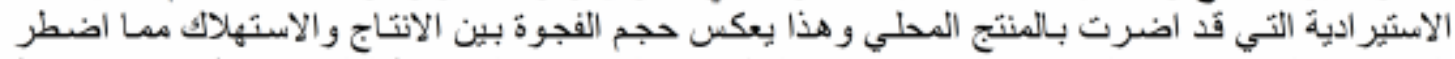

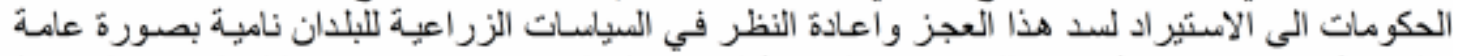

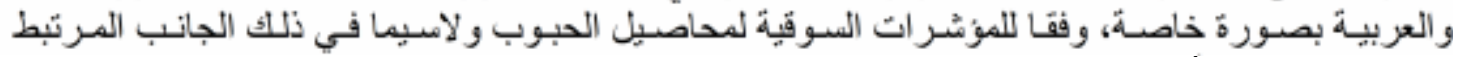
بالحبوب الغذائية لتأمين اقصى المستويات من الامن الغذائي في اقتصاداتهم المحلية. 


\title{
SOURCES OF PRODUCTION AND CONSUMPTION GAP OF MAIN GRAIN IN IRAQ AND OTHER NEARLY COUNTRIES FOR THE PERIOD(1985-2005) \\ "COMPARATIVE ANALYTIC STUDY"
}

Lora B. Basher AI-Saor

Econ.dept., college of Agric. And Foresty, Mosul Univ.,Iraq.

\begin{abstract}
Food security considers unsufficiency of agricultural production for consumption needs are one of the important affairs that face the Arab nation for its direct effects on the economic, social, political and enrironoment positions together with the associated developing decision.Arabic states produced an agricultural politic,for developing the different agricultural sectors and for support food security tracts. In addition, it is adaptation increcosing direction toword emancipating the economics and privatization the production sectors on food goods that has an importance in nourishment and economical side on Iraq and the choosed countries.

The study aimes at anylaizing and restricting the gap sources in production and consumption for main grain crops during (1985-2005) in iraq and the near by countries to know the relative importunce of these resources and using the index analysis procedure to account the variable values which appear in each country a lonely. On the light of available data the variable could be described and studied which included the normative decline of grain production for three years ago and real income rate of a person also comparative advantage for deficit and surplus of balance of payments to the total local production, again comparative advantage for deficit and surplus for common budget to total local production . the results appeared that the significant and non significant in its effected on food gap size of grains for Iraq and the choosed countries.Via this study we have reach some of results and recommendations.

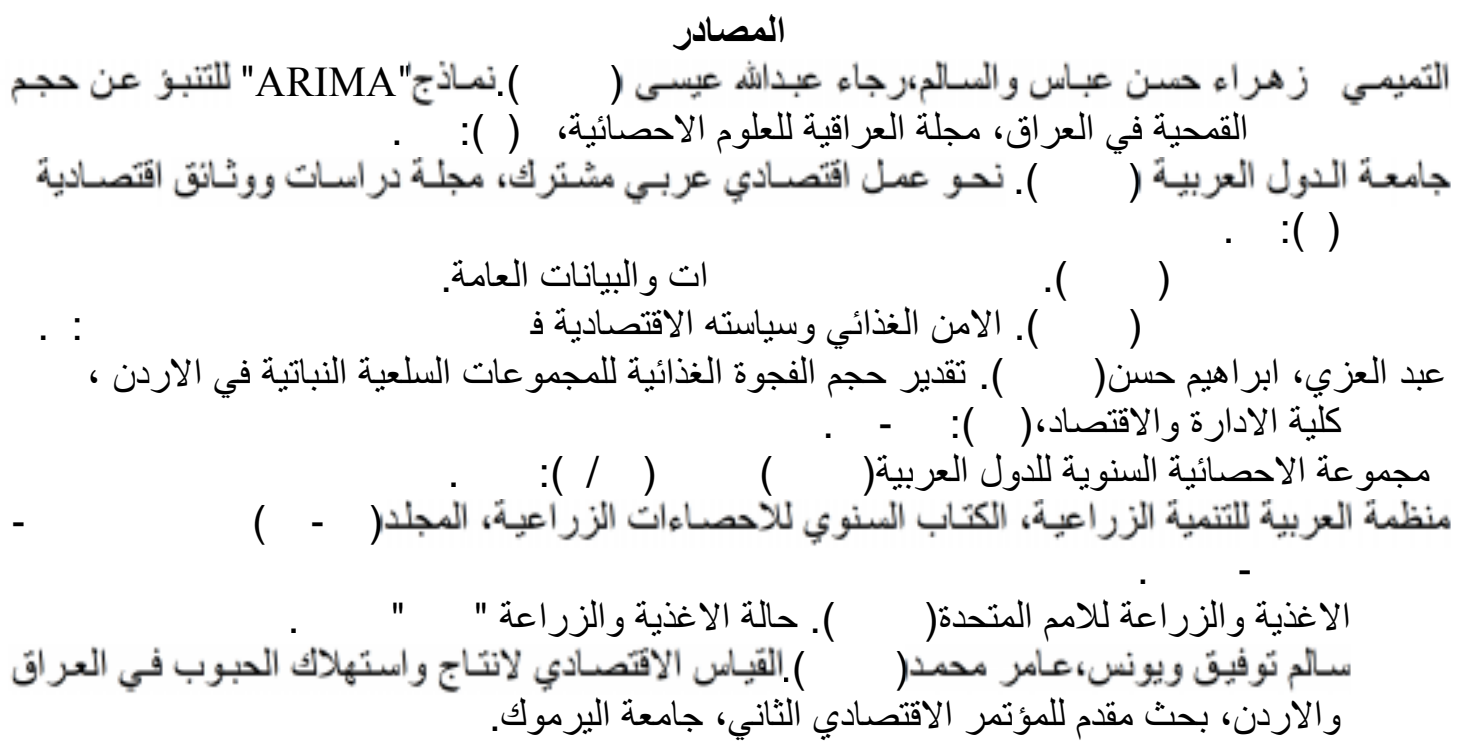




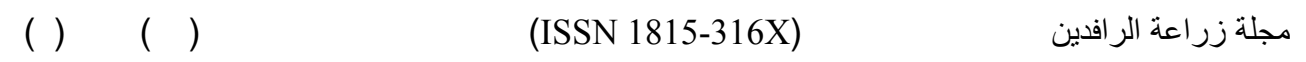

$$
\begin{aligned}
& \text { النجفي ، سالم توفيق( .المتضمنات الاقتصادية للامن الغذائي و الفقر في الوطن العربي،اشكالية }
\end{aligned}
$$

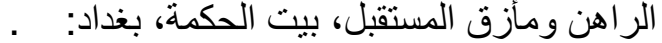

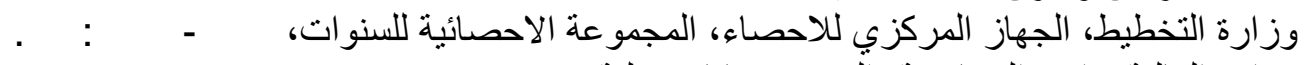

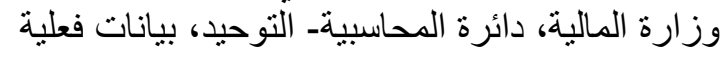

United nation(1995).FAO,Food outlook, Food And Agriculture Organization of the UN,October, Rome. 